\title{
Vol
}

SOUTHEAST ASIA

\section{Vietnamese Businesses Study 'Innovation' to Move Ahead}

06 January 2015 Marianne Brown VOA News

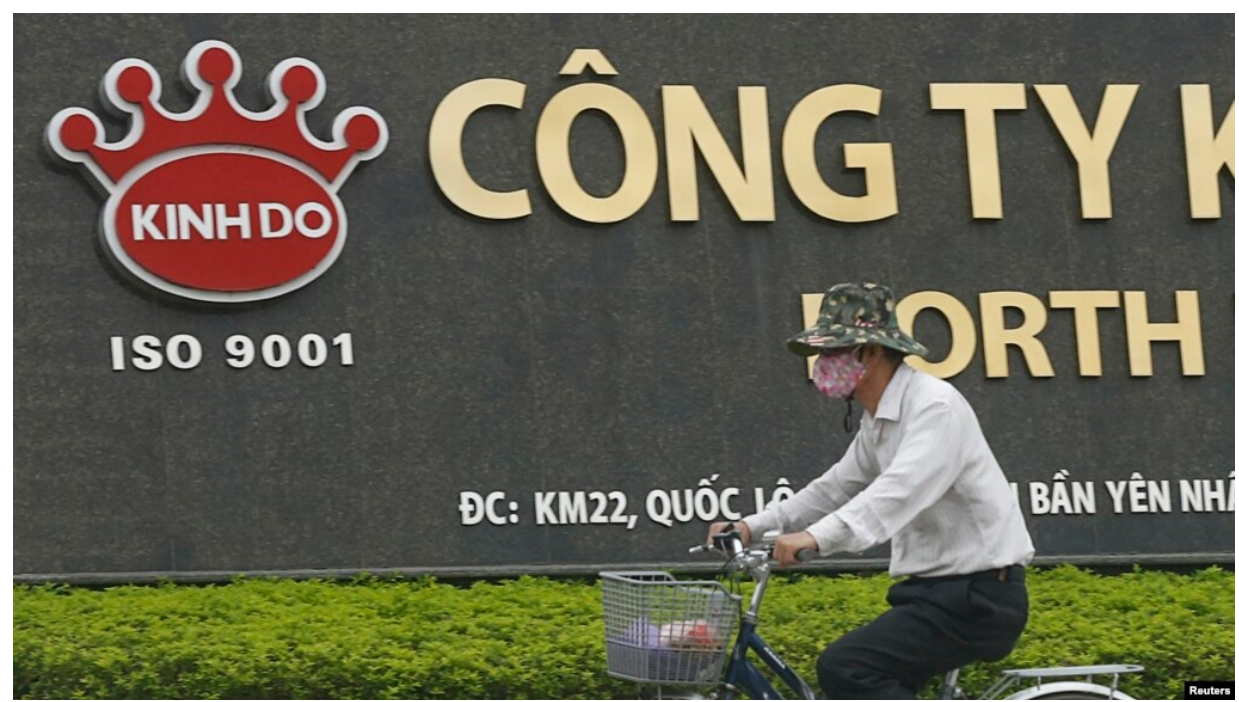

FILE - A man rides a bicycle past a Kinh Do factory in Vietnam's northern Hung Yen province, outside Hanoi.

HANOI - Encouraging innovation has become a buzzword for developing economies like Vietnam, where companies are trying to learn from modern business practices in order to boost profits. To help, a group of Vietnamese economists have devised a survey which measures how innovative businesses are and how they value innovation.

Hundreds of bottles of rice wine are labeled at family-owned factory Phu Le in Ben Tre province, in south Vietnam. The company is named after the village where they employ residents to undertake the initial fermentation process. 
"Every Thursday we receive about 5,000 liters. We have four groups of villagers, each group of about 10 villagers, they take their product here," said deputy director Le Thanh Truc.

The company has built a customer distribution network through the villagers, and is trying to promote its brand through word-of-mouth rather than impersonal advertising campaigns. A big part of that is having a strong relationship with producers and consumers.

"I share the information with all people in my company and my customers' distribution channel... I devise the way to collect new ideas. Both workers and managers, all. We collect ideas by meeting together. I have some channels to collect information, email, Facebook, share the ideas and after we collect that we have a meeting every month to talk about that," said Truc.

The company also took part in the i2Metrix survey, launched last year, which assesses businesses capacity for innovation in 10 areas, including the quality of human resources, levels of organizational support, and levels of adaption to market trends.

The idea is that this assessment can help businesses utilize innovation better to boost their competitiveness.

The survey offers deeper understanding of what innovation means, which is very important for Vietnamese businesses, said co-founder Tran Tri Dung.

"If you ask Vietnamese people, especially entrepreneurs and business people, 'Is innovation important?' They immediately tell you innovation is the most important. But then when you ask them, 'How do you innovate?' They cannot answer," said Dung.

A lot of this has to do with the education system, which traditionally has been based on rote-learning and has not encouraged creative thinking. 
"Most people perceive innovation as something like overnight result: after one night $[\mathrm{a}]$ beautiful thing comes. But what we are now trying to disseminate is that innovation is a tedious process that requires a lot of patience and principle and methodology. Without that you can't achieve your dream," said Dung.

Dozens of companies have taken part so far, ranging from startups to large state-owned businesses, including one outsource company in An Giang province which makes police uniforms for the United States.

Innovation has implications on a national level too, and can help avoid the "middle income trap," an economic situation where a country is able to attain a certain income but gets stuck at that level.

Vietnam has had a very good track record of economic growth. But much of it over the last 10-15 years has been from the exploitation of natural resources and from foreign direct investment.

Now, those sources of growth need to be diversified, said Suhas Parandekar, Senior Education Economist for the World Bank.

"Vietnam has reached a stage where you need to have a deeper diversity in types of products, in product categories. With innovation you have higher productivity, higher diversity in production in the types of goods that are made and that's a way to increase prosperity and growth," said Parandekar.

As the economic engine of California's Silicon Valley attests, a lot of innovation around the world comes from startup companies. However, innovation is relevant for all kinds of enterprises, Parandekar pointed out, and in Vietnam that includes state-owned businesses.

"I don't think you can say that X cannot innovate. In fact in a modern complex economy every company needs to innovate," said Parandekar.

Le Thanh Truc said taking part in the survey helped her think more carefully about the way they do business. The team hopes this year many more businesses will be saying the same thing. 
